\title{
Religión, fiestas y Centros Ceremoniales mayas de la Cruz Parlante
}

\author{
Religion, Parties and Mayan Ceremonial Centers of "la Cruz Parlante"
}

\author{
Manuel Buenrostro-Alba
}

Resumen: En el trabajo se describe el principal santo de los mayas de Quintana Roo, la Cruz Parlante, así como los centros ceremoniales y las fiestas tradicionales relacionadas con esta advocación. Se incluyen datos etnográficos que describen el contexto en el que se centra el estudio. La CruzParlante permite a los mayas de Quintana Roo seguir existiendo y los protege, pero para ello debe estar custodiada por los propios mayas.

Palabras clave: mayas, religión, centros ceremoniales, compadrazgo, organización social.

Abstract: The paper describes the Mayan ceremonial centers and traditional festivals of the Maya of Quintana Roo. Ethnographic data describing the context in which the study focuses are included. The text addresses the description of the principal saint of the Maya: the talking cross, this deity is a fundamental symbol of Mayan religion. The talking cross allows Maya continue to exist, protects them, but this must be guarded by the Maya themselves.

Keywords: Maya, religion, ceremonial center, cronyism, social organization.

Manuel Buenrostro Alba, doctor en Antropología por la Universidad Nacional Autónoma de México. Profesor-investigador en la Universidad de Quintana Roo, México. Temas de especialización: pueblos indígenas, etnografía, antropología jurídica, derecho indígena, mayas. Coreo electrónico: buenrostro_manuel@yahoo.com.mx.
Enviado a dictamen: 20 de enero de 2015.

Aprobación: 20 de abril de 2015.

Revisiones: 2. 


\section{Introducción}

$\underset{\mathrm{d}}{\mathrm{d}}$ presente trabajo se centra en una parte de la religión de los mayas contemporáneos de la zona central del estado de Quintana Roo. Particularmente el trabajo retoma datos etnográficos de las llamadas iglesias, santuarios o centros ceremoniales mayas. Se trata de los espacios sagrados en donde se resguarda a su principal santo: la Cruz Parlante. Esto no quiere decir que para los mayas no existan otros espacios sagrados, como los cenotes, la milpa, algunas cuevas, la selva, los sitios arqueológicos y otros lugares sagrados que no se tratan en este trabajo, así como otros tipos de ceremonias aún vigentes, como los bautizos mayas, las bodas o las ceremonias de petición de lluvia o Chak-Chak, pero, debido al limitado espacio de este escrito, no se tratan estos aspectos. Tampoco es posible hacer un recorrido por el estado del arte del tema religioso, ya que eso rebasaría los alcances del artículo.

Por ello, el objetivo del trabajo es describir y analizar los centros ceremoniales mayas dedicados a la Cruz Parlante del centro del estado de Quintana Roo y analizar etnográficamente la importancia de su culto en relación con la organización social de los mayas de este estado mexicano.

Existen cinco centros ceremoniales de la Santa Cruz en todo el estado de Quintana Roo, a los cuales asisten familias de comunidades cercanas para cumplir con su obligación de resguardarla temporalmente haciendo guardias que duran de ocho a quince días. Se trata de Tixcacal Guardia, Chancá-Veracruz, Chumpón, Tulum y Cruz Parlante, que se describen más adelante.

Muchos pueblos construyen su identidad alrededor de la idea que tienen del origen de la humanidad. Por ello, este trabajo trata no sólo de la religión y los centros ceremoniales de la Cruz Parlante, sino de los diferentes espacios en donde se manifiesta esta creencia religiosa.

Para entender lo anterior, es necesario revisar algunos conceptos que dan cuenta de esto, como la idea de "cosmovisión", entendida como una visión estructurada en la cual los integrantes de una comunidad combinan de forma coherente sus nociones sobre su medioambiente y el cosmos. Incluye también concepciones acerca de las fuerzas anímicas del hombre, el cuerpo humano como imagen del cosmos, y está relacionada con el ámbito religioso y las creencias, es decir, con las explicaciones del mundo. Este concepto difiere, por tanto, del concepto de religión (Broda, 2001: 16-17), porque ésta más bien tiene que ver con la organización ceremonial e incluye, además de ideas, instituciones, creencias y actuaciones, un sistema de acción, de vida social.

Por otro lado, el ritual es el vínculo entre la cosmovisión y el hombre, es parte importante de la religión e involucra la participación social. A través del ritual, se dan actuaciones comunitarias y éste incide en la reproducción social.

Vinculado con lo anterior se encuentra la ideología, que establece el nexo entre la cosmovisión y las estructuras sociales y económicas de la sociedad (Broda, 2001: 17).

El ritual, la cosmovisión, la religión y la ideología no son estáticas, sino que son producto de hechos históricos inmersos en procesos de larga duración.

Elconcepto de sincretismo esinsuficiente para reflejar la complejidad de mezclas, símbolos, deidades, sitios sagrados, etcétera. A partir de la Conquista, la religión de los pueblos indios trató de ser reemplazada por la Iglesia católica, lo que condujo a que los ritos agrícolas se trasladaran a los cerros, cuevas, milpas, bosques y selvas. En la actualidad existen cultos que siguen siendo importantes para el campesino indígena, tales como los del agua, la fertilidad o los ciclos estacionarios.

Debido a que la religión forma parte de diversos espacios de la vida de las comunidades indígenas mayas, es importante considerar este aspecto como uno de los que requieren reconocimiento ante las leyes.

Los centros ceremoniales de la Cruz Parlante maya no se pueden entender como espacios aislados del resto de la vida cotidiana de la población indígena. Elio Masferrer, cuando se refiere a la religión de los pueblos indios, prefiere denominarla "espiritualidad indígena" ya que, según él, este concepto es más cercano a la religión practicada por los pueblos indios (Masferrer, 2002: 147). 


\section{Cosmovisión maya, expresiones actuales en Quintana Roo}

La forma en que los mayas de Quintana Roo han construido la idea de su origen o cosmovisión está directamente vinculada con aspectos religiosos y ha ido cambiando con el paso del tiempo. En este artículo se pretende describir brevemente la cosmovisión de los mayas y su expresión en la actualidad, además de algunas ideas e historias que rodean su vida en relación con las fiestas y rituales realizados, en especial, durante el culto a la Cruz Parlante.

Los mayas contemporáneos han aprendido mucho de sus antepasados lejanos y cercanos y frecuentemente hacen referencia a las historias que les contaban sus padres, sus abuelos y los abuelos de sus abuelos, porque aun los mayas más ancianos todavía recuerdan lo que les decían sus antepasados.

Algunas fiestas mayas han ido cambiando, pero la mayoría, según los propios mayas afirman, conserva su esencia desde hace muchos años. Por otro lado, no en todo el territorio maya se realizan las mismas fiestas y rituales, sino que en cada región se practican en tiempos y formas diferentes. A pesar de ello, existen algunas ceremonias que sí pueden considerarse como fiestas de todos los mayas del estado de Quintana Roo.

La mayoría de las prácticas religiosas de los mayas se concentra en las iglesias mayas o centros ceremoniales. Nos centraremos en estos últimos, también llamados santuarios, que resguardan la Cruz Parlante y que tienen su origen en la Guerra de Castas. Sobre este culto, Lorena Careaga señala que se trata del “[...] conjunto de creencias y prácticas religiosas que caracterizan a un grupo maya particular de Quintana Roo: los herederos de los rebeldes de la Guerra de Castas [...]" (Careaga, 1998: 109). Esta misma autora menciona que el fenómeno religioso maya está constituido por la unión entre el conjunto de creencias y prácticas que datan de la Guerra de Castas, y el conjunto de prácticas religiosas agrícolas, cuyo origen es más antiguo. De esta forma, la religiosidad maya actual está formada por elementos mayas y cristianos (Careaga, 1998) y por aspectos religiosos y políticos.
El origen de la Cruz Parlante, entonces, se remonta a la Guerra de Castas, rebelión maya que inició en 1847 en contra de la población no indígena que había sometido a los mayas durante varias décadas. La cruz apareció en un cenote y, a través de un ventrílocuo, hablaba a los mayas para guiarlos en su lucha, los animaba para que no se dieran por vencidos y les prometía cuidarlos para que salieran vencedores durante los enfrentamientos. Desde entonces, los descendientes de los mayas veneran la Cruz Parlante y para ello la colocaron en los centros ceremoniales que existen hasta la actualidad.

En primer término, nos centraremos en la comunidad de X-Yatil debido a que es una de las más representativas del culto a la Cruz Parlante y porque el sacerdote maya Juan Witzil proporcionó todas las facilidades para obtener información del centro ceremonial. Aunque en toda la zona maya una de las festividades más importantes es la Semana Santa, en el caso de X-Yatil, comunidad ubicada en el municipio de Felipe Carrillo Puerto, esta fiesta no es más importante que la de su santo patrono: san Bernardino. Este santo está representado por una cruz con huipil —dedicada a San Bernardino - que recuerda la imagen y veneración a la Cruz Parlante de la Guerra de Castas.

La religión es uno de los elementos identitarios que une a los mayas de Quintana Roo y, en el caso del culto a la Cruz Parlante, les permite vincularse a través de los centros ceremoniales y de las redes construidas en torno a ellos. Desde sus inicios, los sacerdotes de los diferentes centros ceremoniales invitan a los participantes de los demás centros a sus fiestas tradicionales. Por ejemplo, la población de X-Yatil antes hacía guardias en otros centros ceremoniales. Sin embargo, en la actualidad son menos frecuentes esos intercambios. El sacerdote de X-Yatil comenta su experiencia así:

Anteriormente, en 1915, era en Tixcacal donde iban a hacer su servicio pero sólo que, por desgracia, en Tixcacal hubo división entre la gente. Entonces vio eso mi abuelo y dijo: "así no hay una reunión sana, no hay felicidad". Algunos, dicen los ancianos, casi no entienden ni ven bien que uno vaya, pero hay algunos no tan ancianos que dicen que uno va a 
hacerse tonto. Así, ipara qué va?, por esas cosas que dicen. Mi abuelo dice: "no hay como Dios, hasta aquí lo podemos adorar, pero como es nuestro deber de cuidar a nuestro grandísimo señor, vamos a ir". Entonces, como Tixcacal es antiguo, nosotros íbamos. Yo iba a Tixcacal, iba a llevar mi promesa, tenía diecinueve años, pero dejé de ir porque decían muchas cosas a uno. No todos lo decían, pero sí había quien decía que, porque uno es tragón, por eso iba a comer el puerco que mataban, la tortilla, el elote. Por eso dicen que uno va. Entonces eso escuché y dejé de ir (entrevista a sacerdote de X-Yatil, 2014).

Cada centro ceremonial de la Cruz Parlante cuenta con cuarteles para que pernocten los mayas que llegan desde diferentes comunidades para la custodia, actividad que recibe el nombre de "hacer guardia". Durante las fiestas, estos cuarteles no son suficientes y acomodan a la gente en donde se pueda. Sin embargo, el sacerdote de X-Yatil consideró que los trataron mal sus propios colegas en otros centros y por eso decidieron ir a hacer su guardia al centro ceremonial de Felipe Carrillo Puerto - Cruz Parlante-, pero ahí tampoco se sintieron a gusto, como veremos a continuación.

Pero cuando nos quedamos allí mucha gente dejó de llegar. Creo que 78 quedamos cuando nos reuníamos ahí. Entonces ahí nos reuníamos, aunque sólo en la casa que tenían hecho a su lado, que le dicen el "cerro de al lado", y otra casa que tenían hecho. Sólo ahí nos quedábamos. Nos tocó una ocasión que cuando hacíamos rezo llovió y nos mojamos. La grasa del pollo manchó todo mi pantalón. Entonces, le dijimos a don Sixto que haga la casita y, si está de acuerdo, vamos a cortar el huano, y él dijo que está de acuerdo. Fuimos a Xpichil a preguntar y dijeron que sí nos dan permiso. Entonces fuimos a cortar los huanos en el ejido de Xpichil y después nos pusimos a construirlo. Lo enhuanamos y los que se molestaron hace como cuatro años y medio están dolidos porque no estuvimos de acuerdo en que nombraran a otro general. Pero es que la costumbre que tenemos desde que decían que uno es general o capitán, desde que esté vivo no se puede cambiar. Porque cuando digan general a una persona o sacerdote maya o al comandante, se encienden trece velas, se hace la oración maya, se ofrece a Dios de que esa persona va a hacer su servicio como comandante, teniente, cabo o general o algo así. Pero no lo pueden quitar, sino hasta que se muera se le busca su sucesor, se encienden las velas, se ofrece también, y como así lo sabíamos, nos preguntábamos qué es lo que íbamos a hacer, está viva esta persona y lo vamos a cambiar, no está bien. Entonces muchos decían que no se puede. Entonces, como no nos pusimos de acuerdo, dijeron que nos iban a cerrar la iglesia y fuimos a entregar gracias a Tixcacal y a nuestro patrón don Isidro (entrevista a sacerdote de X-Yatil, 2014).

Aunque parece que la razón por la que la compañía de X-Yatil dejó de hacer su servicio en otros centros ceremoniales fueron los malos tratos, en el testimonio también se aprecia que al interior de la organización social basada en los centros ceremoniales existen desacuerdos por diferentes razones, lo que puede llevar a la creación de nuevos centros ceremoniales.

Otro aspecto que está en el trasfondo de la problemática tiene que ver con los apoyos económicos que otorga el gobierno del estado a los dignatarios mayas que participan en el sistema de guardias, lo que, más que beneficiarlos, los ha dividido en una lucha por esos recursos, que además son mínimos.

El gobierno del estado ha tratado de ganarse la simpatía de los mayas de Quintana Roo para conseguir votos durante los procesos electorales otorgando apoyos, tanto en efectivo como en despensas, que para algunos mayas son importantes. Aunque se trata de una utilización política por parte del gobierno, los mayas han aprendido a sacar beneficio de ello; sin embargo, las estrategias políticas oficiales les siguen dividiendo.

Una institución muy importante en la organización social maya relacionada con la religión es el compadrazgo, el cual tiene que ver con el apadrinamiento de los hijos de una pareja y se lleva a cabo en la ceremonia religiosa del bautizo o jéets méek'. Aunque regularmente se busca que los compadres tengan afinidad con la pareja, pueden tomarse en cuenta otros requisitos o criterios 
para seleccionar a los compadres, como los que señala Alfonso Villa:

Las personas seleccionadas para esta misión deben reunir como requisitos esenciales los que siguen: ser pareja casada, de buena reputación y de solvencia moral reconocida; sin embargo, en caso de existir todavía los abuelos de la criatura por nacer (de preferencia los del lado paterno), entonces, el problema queda resuelto por ser ellos los más indicados para servir de padrinos... Desde el momento en que aceptan esta misión, las personas escogidas pasan a ser compadres de las que solicitan el favor. La importancia de esta relación queda expresada mediante actos y ceremonias especiales [...], en todas ellas se ponen de manifiesto la subordinación y gratitud de los que piden el favor a los que lo otorgan (Villa, 1987: 260-261).

Dada la situación que se vive en la actualidad, la posición económica de los candidatos a padrinos es un factor relevante en el momento de la selección. El que la pareja esté casada o no, no es un requisito de importancia en la actualidad; lo que destacan los mayas es que sus padrinos puedan llegar a ocupar el rol de sus padres en caso de que no se cuente con ellos, ya sea por migración temporal, por enfermedad o por fallecimiento. Tanto a los padres como a los padrinos se les debe el mismo respeto, y los padrinos de bautizo adquieren una responsabilidad de por vida hacia los ahijados.

Por otro lado, en las bodas se busca tener padrinos de casi todo lo que conlleva una fiesta de matrimonio, la cual es cada vez más semejante al tipo de fiesta occidental, por lo que se eligen padrinos de pastel, de luz y sonido, de cojines, de lazo o de anillos, entre otros objetos y elementos de la fiesta. Sin embargo, aunque se han incorporado estos nuevos aspectos, la esencia de la boda maya se mantiene y se cumple con el ritual maya durante la unión de la pareja. Posteriormente, los padrinos pueden llegar a aconsejar a la joven pareja en caso de presentar dificultades durante los primeros años de matrimonio.

Esto tiene que ver con el hecho de que "los mayas peninsulares han incorporado a su antiguo sistema de parentesco diversos elementos del sistema occidental debido a la creciente influencia de la cultura nacional, provocada por el contacto cotidiano y constante con la sociedad mestiza y con las instituciones estatales" (Quintal, 2003: 306). Sin embargo, la esencia del ritual religioso y de las relaciones de parentesco se mantiene.

En este sentido, la institución del compadrazgo o parentesco ritual sigue siendo un mecanismo que sirve para reforzar, renovar y acrecentar o extender los vínculos consanguíneos y de alianza. Una de las principales formas de establecer el compadrazgo es el ritual del jéets méek', el cual consiste en cargar a un niño o niña a horcajadas, o sea, sobre la cadera. Se piensa que esta costumbre tiene sus orígenes en el periodo prehispánico, aunque en la actualidad se sigue practicando como un rito de iniciación. Sobre este ritual, Ella Fanny Quintal plantea lo siguiente:
La ceremonia, aunque se aduce es "para fortalecer los muslos y las piernas del recién nacido y para asegurar que crezca fuerte y sano", en realidad contiene un mensaje simbólico por el cual el grupo familiar acepta la responsabilidad de educar al infante en el marco de la cultura indígena, según los papeles de género aceptados. O sea, este ritual otorga al pequeño una identidad que perdurará para el resto de su vida. La ceremonia del jéets méek refuerza o encasilla a la criatura en su orientación social como varón o como mujer y es ejecutada, como se mencionó, hasta que el infante es suficientemente fuerte y apto para soportar la carga del papel sexual y genérico que le corresponde (Quintal, 2003: 311).

Esta ceremonia se lleva a cabo durante los primeros meses del niño o la niña, aunque hay ocasiones en que se espera a que cumpla el año, ya que también se asocia a la creencia de que el ritual lo prepara para dar sus primeros pasos. El ritual es de los primeros que identifica a los mayas con su organización social y sus creencias religiosas.

Por otro lado, los mayas contemporáneos de Quintana Roo se organizan a través de compañías religiosas 
alrededor de centros ceremoniales. Herencia de la Guerra de Castas, mantienen esta forma de organización, la cual coexiste hoy en día con nuevas autoridades y cargos que se han ido definiendo a lo largo de los años, como es el caso de los jueces tradicionales mayas.

\section{Centros ceremoniales de la Cruz Parlante}

A partir de la aprobación de la Ley de Derechos, Cultura y Organización Indígena del Estado de Quintana Roo en 1997, se define centro ceremonial como: "el lugar sagrado de los indígenas mayas en donde practican su religión, llevan a cabo sus ceremonias tradicionales y sus diversas expresiones culturales" (Ley de Derechos, Cultura y Organización Indígena del Estado de Quintana Roo, 2007: 9).

Esta ley, en su artículo 45, reconoce los siguientes centros ceremoniales:

- Tixcacal Guardia,

- Chancá-Veracruz,

- Chumpón,

- Tulum,

- Cruz Parlante.

Sin embargo, más adelante la ley destaca que también considera aquellos otros centros que reconozca el Gran Consejo Maya, el cual está integrado por representantes de los diversos centros ceremoniales. Este consejo no ha operado como se tenía pensado originalmente, porque poco después de su creación se disolvió debido a que sus miembros no fueron reconocidos por algunas comunidades. A partir del año 2009 diversas instituciones estatales han buscado su reactivación, no así los propios mayas, quienes no ven utilidad a esta organización.

Las características de los actuales centros ceremoniales de la Cruz Parlante son las siguientes:

Tixcacal Guardia. Se trata de uno de los centros ceremoniales más representativos de la región de Quintana Roo. Algunos mayas consideran que este centro es el que alberga a la Cruz Parlante "original", o sea la que se apareció y habló por primera vez en
1847, aunque de hecho no está a la vista de nadie. El centro ceremonial cuenta con una iglesia, lugar donde se realizan los rezos y se resguardan los santos, y sus cuarteles, que sirven para albergar a las compañías que acuden a "hacer guardia" a lo largo del año. Las guardias son obligatorias y consisten en que los mayas adscritos a este centro ceremonial acudan a rezar y custodiar a los santos. Las guardias duran entre cinco y ocho días por cada compañía, y las diferentes compañías se van rotando. Se dice que es representativo porque las autoridades religiosas han tratado de mantenerse separadas del gobierno y sus representantes, así como de toda persona externa. Son muy reservados respecto al acceso a la iglesia y, como en todos los demás centros ceremoniales, para entrar tanto propios como extraños deben quitarse los zapatos y descubrirse la cabeza de sombreros o gorras.

Además, los guardias tienen la facultad de otorgar el permiso para acceder, sobre todo si se trata de personas ajenas a la comunidad. En este sentido, incluso colocaron un letrero de madera a la entrada del centro ceremonial que dice: "este centro ceremonial ha sido construido y remodelado sin la ayuda de ninguna autoridad externa, ni de ningún gobierno". No obstante, hoy existen dos santuarios en la comunidad: el primero de ellos es el que históricamente ha existido, y el segundo es una iglesia construida en el terreno del juez tradicional llamado Pedro Ek, la cual comenzó a funcionar en diciembre de 2007. Esto fue posible debido a que la compañía que se organizaba bajo el antiguo centro ceremonial desconoció al juez y sus funciones, por lo que él decidió construir su propio centro ceremonial. Además, ahora se autonombra general, que es el cargo más alto para los mayas. Obviamente, cuenta con varios seguidores que lo reconocen como juez, y ahora como general maya.

En la comunidad se realizan tres fiestas importantes a lo largo del año. La principal es la que se celebra del 24 de abril al 3 de mayo en honor de "las tres cruces", la segunda fiesta se realiza en honor de la virgen María del 23 al 29 de agosto, y la tercera se celebra del 6 al 13 de diciembre en honor de la virgen María de la Concepción.

Chancá Veracruz. En este centro ceremonial se encuentra uno de los generales mayas más reconocidos 
por todos los indígenas de la región. Como se ha mencionado, el cargo de general es el rango más alto para los mayas y ellos consideran que sólo debe existir un general en toda la región. También es uno de los centros ceremoniales más reservados en cuanto al acceso y custodia de los santos, incluyendo las cruces. Cuenta con cuarteles para alojar a los que hacen guardias. Durante su fiesta tradicional, que se celebra del 15 al 20 de abril en honor a las Tres Cruces, organizan corridas de toros, y varios "cabos" y "soldados" son los responsables de mantener el orden en la fiesta. A través de altavoces, comunican a todos los asistentes a la fiesta que está prohibido tomar fotografías, no sólo en el centro ceremonial y sus alrededores, sino también en las procesiones y corridas de toros. En una ocasión, una persona externa tomó una foto de la corrida de toros con su teléfono celular tratando de engañar a los mayas y le confiscaron el teléfono. Posteriormente, la dueña del teléfono puso una denuncia en la cabecera municipal, citaron a los responsables y éstos llevaron el teléfono para entregarlo, aclarando que sólo lo confiscaron durante la fiesta. La dueña del teléfono dijo que se lo habían devuelto roto y pedía que le pagaran tres mil pesos para reponerlo; sin embargo, no pudo demostrar que efectivamente las autoridades tradicionales le hubieran dañado su teléfono, por lo que no se le pagó nada y, al contrario, se le advirtió de que no volviera a tratar de engañarlos ni a tomar fotos de las fiestas tradicionales sin consentimiento.

Chumpón. Localizado en la llamada ruta de los Chunes, es uno de los centros ceremoniales que tiene más prestigio para los mayas. Por su ubicación, mantiene más contacto con el centro ceremonial de Tulum. No se puede acceder en cualquier momento porque, aunque todo el tiempo cuenta con guardias, sólo se puede entrar cuando hay rezo. El acceso a la iglesia es limitado para los no mayas. Cuenta con cuarteles para albergar a los guardias. En los últimos años, y con la apertura y pavimentación de caminos hacia la comunidad, la maquinaria y el cascajo forman parte del paisaje que ronda el centro ceremonial. Su principal fiesta se lleva a cabo del 1 al 12 de mayo en honor de las Tres Cruces.
Tulum. Localizado en un pueblo turístico cercano a la zona arqueológica del mismo nombre, mantiene su solemnidad y el acceso está restringido. Aunque se permite el ingreso a personas no mayas, en la entrada hay un guardia que vigila en todo momento el comportamiento de la persona y le explica que debe entrar en silencio, llevar una vela para encenderla en el altar, y entrar descalza y con la cabeza descubierta. En Tulum se realizan dos grandes fiestas al año, la primera del 7 al 14 de marzo en honor de las Tres Cruces, y la segunda del 7 al 11 de octubre en honor de la Virgen de la Concepción.

Cruz Parlante. Aunque es un centro reconocido por la Ley de Derechos, Cultura y Organización Indígena del Estado de Quintana Roo, muchos mayas no lo reconocen. Se localiza en Felipe Carrillo Puerto, la cabecera del municipio del mismo nombre, en el centro de la llamada zona maya. En este centro ceremonial se llevan a cabo las mismas actividades que en los demás en cuanto a rezos, guardias y fiestas. No obstante, en los últimos años han disminuido las guardias de los mayas al considerar que no es un "verdadero" centro ceremonial, por lo que han dejado de ir y se han adscrito a otros. Realiza dos fiestas importantes al año: la primera del 26 de abril al 3 de mayo en honor de la Santa Cruz, y la segunda del 5 al 12 de enero en honor de los Tres Reyes. También está prohibido entrar con zapatos y tomar fotografías.

Estos son los cinco centros ceremoniales reconocidos por la Ley de Derechos, Cultura y Organización Indígena del Estado de Quintana Roo, aunque han existido desde mucho antes que la ley mencionada. En este sentido, es importante destacar que en la actualidad no sólo son espacios sagrados para los mayas que participan en el sistema de guardias, sino que se ha avanzado en el reconocimiento de dichos espacios por el Estado.

Como se ha indicado, en todos los centros ceremoniales se siguen ciertas reglas de comportamiento. Por ejemplo, no se puede entrar con zapatos, sombreros ni gorras y está estrictamente prohibido tomar fotografías e introducir cámaras de video o grabar con ellas en el interior y el exterior del centro. El control lo ejercen los guardias, que pueden confiscar las cámaras 
que los visitantes utilizan a pesar de la advertencia. Aunque el acceso es libre, no en todos los centros se permite la entrada en cualquier momento. En algunos es más fácil entrar cuando se llevan velas y se pide permiso para encenderlas a los santos. En los centros ceremoniales de Tulum, Chancá Veracruz, Tixcacal Guardia y Chumpón se organizan las fiestas de tal manera que las fechas no choquen entre sí para que las autoridades tradicionales mayas puedan asistir a todas sin descuidar sus centros ceremoniales.

Sin embargo, como se ha mencionado previamente, para los mayas de Quintana Roo no sólo los centros ceremoniales son espacios sagrados, sino que también tienen altares, entre otros lugares, en sus milpas y en sus casas. Según el sacerdote de X-Yatil, el altar representa un lugar sagrado, por eso se coloca el santo en forma de cruz. La cruz representa un santo que puede ser de género femenino o masculino, aunque siempre se cubre con un huipil. También es un lugar en donde se llevan a cabo rezos. Durante la fiesta tradicional, las familias que cooperan con comida para repartir la colocan en el altar de su casa. Cuando se va a recoger la comida, se hace una pequeña procesión en la que participan sacerdotes, rezadores, músicos, vaqueras ${ }^{1} \mathrm{y}$ voluntarios para ir a buscar la comida, la cual se lleva en cubetas, ollas, jícaras y platos; también se llevan tortillas hechas a mano envueltas en servilletas. Alllegar a la casa que proporciona la comida, se hace un rezo que dura entre diez y quince minutos en el altar de la casa. La comida es una ofrenda que se entrega en forma de "promesa", es decir, cada familia hace una promesa cada año y proporciona comida durantela fiesta por el cumplimiento de favores recibidos. Posteriormente se recolecta la comida y se lleva a la iglesia nuevamente en procesión. Toda la comida se concentra en la iglesia maya y al terminar los rezos del día se reparte entre todos los participantes de la fiesta, lo que se anuncia tocando las campanas. Algunas familias que no llegan al rezo aparecen, cuando escuchan las campanas, con cubetas o trastes limpios para llevarse una parte de la comida a sus casas, mientras que otra parte se consume en la iglesia.

Por otro lado, hay muchas iglesias mayas que son consideradas como centros ceremoniales aunque no sean reconocidas por la ley ni por las autoridades de otros centros ceremoniales.

\section{El caso del centro ceremonial de la Cruz Parlante de X-Yatil}

A continuación ilustraremos la "compañía” de X-Yatil. La organización actual de los mayas se realiza a partir de los centros ceremoniales, los cuales constan de varias "compañías", cada una de las cuales incluye cargos político-religiosos cuya obligación es hacer guardias en los centros ceremoniales a los que pertenecen.

En el caso de X-Yatil, durante varios años perteneció al centro ceremonial de Felipe Carrillo Puerto, dedicado a la Cruz Parlante, aunque también hacían servicio en los otros cuatro centros ceremoniales. El servicio consiste en hacer guardias y rezos durante varios días custodiando el centro ceremonial y a los santos que ahí se resguardan.

A la cabeza de todos los centros ceremoniales está un general, quien se encarga de liderar a todos los mayas. Los dignatarios de X-Yatil reconocen al general Santiago Cruz Peraza, quien pertenece a la comunidad de Chancá Veracruz. Para ellos, él es el único general y no debe haber más. Sin embargo, en otros centros ceremoniales y comunidades han nombrado a otros generales, como el general Victoriano Yeh Ake, de la comunidad de X-Hazil Sur, y José Chi Uc, de la comunidad de Uh-May, ambos pertenecen al centro ceremonial Cruz Parlante; el general Jacinto Pech Collí, de la comunidad de X-Pichil, perteneciente al centro ceremonial de Tixcacal Guardia; o el general Sixto Balam Chic, de la comunidad de Señor, perteneciente a la compañía de X-Yatil. Ninguno de ellos desconoce al general de Chancá Veracruz. Como se mencionó más arriba, recientemente se autonombró general el juez tradicional de Tixcacal Guardia, Pedro Ek Cituk, quien además ha construido una iglesia en su propio terreno, junto al juzgado tradicional. Es obvio que esto no lo ha hecho solo, sino con el apoyo de un sector de la comunidad que simpatiza con él.

En cuanto a jerarquía, debajo del general se encuentran las diferentes compañías, como la compañía 
de X-Yatil, que reconoce al general de Chancá Veracruz, y que tiene los siguientes integrantes:

- tres sacerdotes mayas: Juan Witzil Cimá, quien además es el juez tradicional, Epifanio Cimá Pech y Marcelo Cimá Balam,

- tres rezadores: Pastor Cimá, Catalino Pool y Wenceslao Urich Pool,

- un comandante: Enrique Catzin Cach,

- un teniente: Asunción Urich Cach,

- un cabo: Efrén Marcos Herrera Pech,

- un sargento: Serapio Cach Balam,

- un capitán: Concepción Chi Uech,

- veintidós soldados,

- cinco músicos: Casiano Pat Aké, Claudio Martín Tuz, Policarpo Aké Pool, Artemio Martín Ché y Diego Martín Ché y

- siete viudas. $^{2}$

Todos los cargos anteriores conforman la compañía de X-Yatil, y cada uno de ellos desempeña un papel importante en la realización de las fiestas y en el funcionamiento y cuidado de la iglesia maya de la comunidad.

El sacerdote y rezador de esta comunidad, que también es el juez, describe de esta manera su nombramiento como dignatario maya reconocido por el gobierno del estado:

Ya tiene años, sólo que cuando nos dieron una identificación [credencial], ya tiene ocho años que se nos dio, sólo que se nos dice dignatarios, seguramente para que cualquier persona o cualquier gobierno que no sepa maya lo entienda. Aquí nosotros los dignatarios somos los conocidos como los sacerdotes mayas ya que hacemos el rezo, hacemos la ofrenda al dios de la tierra ya que nosotros hacemos diferentes las cosas, no como lo hacen los sacerdotes que hablan español. Nosotros lo hacemos todo diferente porque tenemos el santo de la tierra, del monte, del agua, del viento. Como del viento, que dicen que es de donde nace el ciclón. Entonces, yo desde que tenía siete años ya sabía toda la oración maya; es que nuestros padres, nuestros abuelos, eran rezadores. Sólo cuando escuché que dijeron nuestros nombres y ya éramos dignatarios mayas para el gobierno. Pues así lo dijeron y para nosotros no está mal. Pero nosotros sólo el rezo es lo que sabemos o tenemos aprendido de cualquier cosa, como lugares del monte, porque en el monte hay lugares donde hay muchas culebras, hay lugares donde dicen que hay vientos, los llamados mal aire, que matan a la gente, le causan a la persona alguna enfermedad. Esas oraciones son lo que sabemos, sólo teníamos ocho años aquí, cuando dijeron que nos iban a dar credencial y nos nombraron dignatarios mayas (entrevista a sacerdote de X-Yatil, 2014).

Los personajes indicados en la lista previa son los que incluso han sido reconocidos por el gobierno del estado aunque, como dice el juez, desde hace muchos años desempeñaban el cargo. El sacerdote tiene muy claro el origen de su centro ceremonial, lo que le ha permitido contar con el respaldo de otros centros ceremoniales y de autoridades tradicionales. Sobre el origen cuenta lo siguiente:

El santo, la Santa Cruz, es la más grande y su nombre es San Bernardino, es él un santo muy antiguo. Posiblemente después de que descubrieron la Santa Cruz en Carrillo Puerto, porque anteriormente las poblaciones pequeñas que están de aquí a Carrillo y Yaxley son pequeñas poblaciones, y dicen que entre una de esas poblaciones, en el tronco de un árbol de habin, un tronco que se quemó todo, se sembró donde se quemó, creo que tres años que se había quemado por completo y seguía floreando y daba frutos. Entonces, como había curanderos [h-men] que eran sacerdotes mayas que decían que tenían poder natural y vieron si era saáca aátal, entonces dijeron que ahí debía hacer una Santa Cruz. Cuando llegó exactamente el día de San Bernardino le cruzaron la Cruz y dijeron que ese era el nombre. Entonces, cuando se quitaron mis abuelos, sus papás y sus abuelos, vinieron a vivir aquí, en X-Yatil. Cuando llegaron, se instalaron y trajeron al santo aquí porque sólo el pozo estaba desde antes, un pozo que está abajo en la terraza, frente a la 
iglesia. Después, al lado del pozo pusieron la iglesia, una iglesia de huano y sus lados de material. Dicen mis abuelos que ellos eran pequeños y sólo miraban que hacían los trabajos, y empezaron entonces a adorarlo y hacían su fiesta, sólo que no en su día, sino que cualquier día era bueno, no como ahorita, que hasta que llegue el tiempo. Anteriormente era el quince de mayo, pero entre diez y quince años [...] comienza el trece de mayo. Pero nada más nosotros lo hicimos así, porque anteriormente, no en cualquier mes, en marzo se le hacía fiesta, o febrero o en abril, hasta que quedó mayo. Es que en mayo se mezcló con las tres cruces, cuando lo vieron en la Santa Cruz, en la Santa Cruz de Balam Nah, era para el tres de mayo. Entonces cuando empieza en abril la fiesta, termina en mayo para que lo vengan a ver (entrevista a sacerdote de X-Yatil, 2014).

Vemos cómo se trata de una iglesia que sigue con la tradición de los centros ceremoniales. Aunque para las personas que llegan de otros lugares la iglesia no es tan antigua, al conocer la historia contada por el sacerdote se corrobora que se contruyó en el territorio en donde se libró la Guerra de Castas. Más adelante nos dice lo siguiente respecto a su santo en forma de cruz.

Este santo es antiguo, creo que era santo cuando se hizo la Guerra de Castas, desde que lo trajeron al pueblo, porque X-Yatil era monte muy alto y había un camino muy feo, el único camino es el que pasa por Xpabil y se va hasta Sabán. Aquí sólo era monte, no había camino. Después se logró unir con el camino español que es el que va a Chunhuhub, que va a Tuk, pero eso era antes porque ahorita ese camino ya se perdió. Entonces es así como empezó X-Yatil, la iglesia, el santo, sólo que hay muchas cosas que ya cambiamos. Se cambió mucho porque anteriormente estaba en la plaza; después, cuando se hizo la carretera, un anciano que hasta ahora vive y es curandero dijo que, como él era el delegado, vamos a mejorar un poco más la iglesia. Dijo que lo derrumben, lo derrumbaron y puso la baldosa y lo destruyó por completo, y pasaron al santo en la iglesia. La casa de don Marcelo Torres, ahí pasaron al santo. Ese lugar es más chico que esta casa; entonces, pidieron un terreno que es donde está ahorita. A don Claudio le preguntaron si vendía un pedazo del terreno para que pongan la iglesia y dijo el anciano que sí, que por qué no, que estaba de acuerdo. Entonces pusieron la iglesia donde está actualmente. Ya tiene como treinta años que la pusieron. Después nos estuvieron contactando las personas que trabajan en el gobierno. En ese tiempo el maestro Germán trabajaba en Chetumal u ahorita está en el INI [Instituto Nacional Indigenista]. Pues como ya nos juntamos, como lo hacían en Tixcacal, Chumpon, Tulúm y Chanca, entonces con esa persona tuvimos un acuerdo y nos reunió en el INI y nos dijo de los programas. Que hay programas que vienen para componer la iglesia, eso es para que no se pierdan los trabajos [tradiciones] y se hizo el escrito y se mandó. Entonces ellos mandaron la forma en cómo se iba a hacer la iglesia y mandaron dinero y, como éramos muchos, dijeron que tiraran la iglesia, y entonces la derrumbaron en su totalidad. Escarbaron los cimientos hasta que apareció la laja. Entonces hicieron la construcción y pusieron grandes piedras para que se pudiera hacer. Entonces, así es como se levantó, y así es como está en la actualidad. Con el dinero que le dieron a otra persona que ya se murió se hicieron las paredes de la iglesia, pero estoy viendo la forma en que estamos organizados, en que me nombraron. Hay muchos católicos y por lo tanto no están de acuerdo con las cooperaciones; están de acuerdo con lo que se hace, pero no van y tampoco dicen si van. Entonces les dije que, como ya hicieron bien las paredes, les dije a don Concepción y don capitán: "vamos a ponernos de acuerdo y le pedimos al gobierno, ya que el INI ya dio el dinero para que hagan las paredes, pues que se ponga techo de lámina, ya que si le ponemos techo de huano no tardaría ni ocho, menos veinte años [...] cuando se pique [el huano...], ¿dónde vamos a conseguir otro si se está picando y estamos más viejos y ya no podemos ir al monte?, icómo lo vamos a componer? Mejor vamos a pedirlo (entrevista a sacerdote de X-Yatil, 2014).

Aunque para el periodo en el que se realizó el trabajo de campo -2014- el Instituto Nacional Indigenista (INI) ya se había transformado en la Comisión Nacional 
para el Desarrollo de los Pueblos Indígenas (CDI), los mayas le seguían nombrando INI. Con estos programas que mencionó el sacerdote lograron algunas mejoras materiales en los templos, pero en muchas ocasiones los apoyos estaban condicionados a que los indígenas pusieran mano de obra, terrenos, materiales y realizaran otros aportes, lo cual sigue ocurriendo en la actualidad. También han condicionado los apoyos a que conserven sus tradiciones, lo que incluye las características arquitectónicas de las construcciones. En el testimonio se aprecia que la CDI planteó que se pusiera el techo de materiales perecederos - huano-, mientras que los mayas argumentaron que era mejor el techo de lámina o concreto para que durara más tiempo. Más adelante nos comentó lo siguiente:

La vez pasada, que le pedimos al pobre hombre que llevaron a México, el ingeniero Mario Villanueva [exgobernador que se encuentra preso], le alcanzamos a pedir la ayuda y él dijo que sí lo iban a venir a ver lo que pedíamos. Cuando nos dijeron que iba a venir el delgado del INI, el licenciado Carlos de Chetumal, entonces vino. [...] Es algo increíble, porque cuando se juntaron fueron como cien o ciento cincuenta. Ninguna vez se ha juntado la gente así, pero se juntó esa cantidad y decían: "estamos de acuerdo". También decía don Erasmo al licenciado: "es verdad, no es que no nos guste el huano, nosotros aquí en techo de huano crecimos, pero tienen razón los compañeros, si ponen la lámina, fácil aguanta quince o diez años. Pero a veces el huano no aguanta y cuando hay humo de entre veinte o veinticinco años, pero sólo cuando hay humo, y, si no, no tarda y ya se está ahuecando". Además, como es fajina, ¿cómo se van a cortarlo? No les importa si la luna esta chica; como sea lo hacen, el caso es que lo hagan. En cambio, cuando es de uno, espera cuando es luna llena para cortar la madera y el huano, pero cuando es fajina es de pensarlo, ya que todo lo hacen, pero lo hacen mal. Entonces es así como se construyó la iglesia y le seguimos pidiendo al licenciado, el gobernador Félix [gobernador en turno], que nos lo teche porque la verdad nosotros sabemos oraciones en maya, y cuando está viniendo algún ciclón le pedimos a Dios que se lo lleve en otro lado, que no toque aquí. Pero pues eso sí se pudo, no tiene que llegar, por eso queremos que sea de material el techo, entonces así sería mejor. Tal vez no lo derrumbe si es grande el huracán que viene, es así lo que queremos para la iglesia (entrevista a sacerdote de X-Yatil, 2014).

Nuevamente se destaca la importancia para los mayas de su iglesia y la forma en que buscan resolver las cuestiones prácticas, además de la vinculación con el gobierno del estado.

\section{Conclusiones}

En este breve trabajo se analizaron los centros ceremoniales de la Cruz Parlante de los mayas de Quintana Roo y se describieron sus características y actividades, así como su forma de organización. Es evidente la vinculación de la religión maya con las actividades cotidianas, aunque en este espacio no se puede abundar con más profundidad.

El principal símbolo religioso de los mayas es la Cruz Parlante, a la que consideran un santo milagroso y a quien le hacen diversos rituales para garantizar que mantenga y cuide a los mayas.

Asimismo, la figura de los sacerdotes mayas es fundamental en la organización social. Los mayas dedican varias horas del día a rezar y lo hacen en silencio, solos o en grupo. Sin importar la forma, gran parte del día rezan a la Cruz Parlante.

\section{Notas}

${ }^{1}$ Las vaqueras son mujeres jóvenes que visten con la ropa tradicional maya: huipil, huaraches y sombreros adornados con listones de colores. Ellas acompañan a los sacerdotes en todas las actividades que realizan.

${ }^{2}$ Las viudas son mujeres que ayudan con la preparación de alimentos, la limpieza de los santuarios y el preparado y lavado de todo lo que se consume. No necesariamente quiere decir que sus maridos hayan muerto. Se les llama así porque tradicionalmente eran las mujeres viudas 
quienes se encargaban de esta labor, pero ahora también mujeres casadas y solteras participan como "viudas" en las fiestas relacionadas con los centros ceremoniales.

\section{Referencias bibliográficas}

Broda, Johanna (2001), "Introducción". En Johanna Broda y Félix Báez-Jorge (coord.), Cosmovisión, ritual e identidad de los pueblos indígenas de México. México: Fondo de Cultura Económica, CONACULTA.

Careaga Viliesid, Lorena (1998), Hierofanía combatiente. Lucha, simbolismo y religiosidad en la Guerra de Castas. Chetumal, México: Universidad de Quintana Roo.
Ley de Derechos, Cultura y Organización Indígena del Estado de Quintana Roo, México, 2007.

Masferrer Kan, Elio (2002), "Los derechos religiosos de las comunidades indígenas". En Jorge Alberto González Galván (coord.), Constitución y derechos indigenas. México: Universidad Nacional Autónoma de México, pp. 147-164. Quintal Avilés, Ella Fanny et al. (2003), "Solares, rumbos y pueblos: organización social de los mayas peninsulares". En Saúl Millán y Julieta Valle (coord.), La comunidad sin limites. La estructura social y comunitaria de los pueblos indígenas de México. México: Instituto Nacional de Antropología e Historia, pp. 291-399.

Villa Rojas, Alfonso (1987), Los elegidos de Dios. México: Instituto Nacional Indigenista. 